\title{
Murmurs of discontent: treatment and treatability of personality disorder
}

\author{
Gwen Adshead
}

"They murmured, as they took their fees 'There is no cure for this disease'."

Hilaire Belloc

Treatability is a confused and confusing concept in psychiatry. In its legal sense, it is a measure that limits the involuntary admission of patients with some particular types of mental disorder. The legal term itself has generated considerable discussion and dissent (e.g. Mawson, 1983; Grounds, 1987), and the Government's White Paper on reforming mental health legislation in England and Wales proposes to abolish it (Department of Health, 2000).

It is, however, a word that also has medical significance. Its use has given rise to another equally confusing concept, 'untreatablility'. This article looks at this concept in more detail and examines its strengths and limitations in relation to personality disorder. It argues that treatability is linked to resources and training, as well as psychopathology, and that different understandings of personality disorder may alter ideas about treatability. This discussion is relevant in the light of the White Paper's proposals and relates also to the Government's proposals for managing dangerous individuals with personality disorder (Home Office, 1999). The discussion, however, focuses on 'treatability' as a clinical term, and does not consider the legal aspects in any detail.

\section{Personality disorder: an illness?}

Box 1 outlines the case of Kieran. Reading this clinical vignette, we might ask, is Kieran ill? And if not, why not? In this article, I will set out some of the arguments about the nosological status of personality disorder in terms of illness and disease.

The debate about personality disorder's status as a mental illness needs to be seen in the context of the more general debate about the extent to which mental distress of any sort can be understood as a disease, illness, disability or disorder. Again, discussions in this area are complicated by the fact that, in English law, 'mental disorder' and 'mental illness' are terms that have specific legal meanings in addition to a more general clinical usage.

\section{Box 1 Clinical vignette}

Kieran is a young man, who has been selfharming for several years, since his lateteens. He regularly presents at different casualty departments around the country, always using different names and giving different accounts of himself. He is also regularly in trouble with the criminal justice system for shoplifting. He attends outpatient appointments to see his psychiatrist and takes prescribed antidepressant medication. Recently, his self-harming behaviour has been getting much worse, and his family want him to be admitted to hospital, involuntarily if necessary. The general practitioner and approved social worker are unsure how best to proceed, as the consultant psychiatrist refuses to admit Kieran, saying: “He's not ill, he's got a personality disorder."

Gwen Adshead is a consultant psychotherapist at Broadmoor Hospital (Psychotherapy Department, Broadmoor Hospital, Crowthorne, Berks RG45 7EG; tel: 0134 754396; fax: 01344 754334) and a consultant psychiatrist at the Traumatic Stress Clinic, Middlesex Hospital. 


\section{Descriptive v. normative} accounts of disorders

The status of mental disorder as illness or disease is still a potent source of debate (for a review, see Fulford, 1989; see also Box 2). Much of the debate has centred around the tension between what are called descriptive and normative accounts. Descriptive accounts of disorders claim that it is possible to describe and classify a disease and/or illness without making some sort of value (or normative) judgement about the concept. Normative accounts claim the reverse: that there is no 'objective' account of disorders that does not contain some reference to an established value or norm. Theorists such as Boorse (1975) have argued that the term 'disease' describes the pathological processes that then give rise to 'illness' as experienced by the patient. 'Diseases' then are those processes that can be described objectively, whereas 'illness' is more subjective, and necessarily involves a normative (value judgement) component.

\section{Biological disadvantage}

This distinction between disease and illness has been highly influential, although still leaving room for debate; for example, whether, and to what extent, the terms 'illness' and 'disease' may actually be synonymous. The arguments become even more complex when applied to mental disorders. Most readers will be familiar with claims that all diagnosis of mental disorder is really 'only' or 'just' a type of value judgement (an argument put most forcefully by Thomas Szasz). Boorse himself suggested that, on this account, it is difficult for any mental disorder to be a disease, although there might be many mental illnesses. Scadding (1988) argued that there may be different overlapping accounts of diseases (syndromal, pathological or aetiological), but that the key feature of a disease is related to the extent to which it puts a biological organism at 'biological disadvantage'. This notion of biological disadvantage has been used to justify the claim that mental disorder has equal disease status with physical disorder (e.g. Kendell, 1975).

\section{Harmful dysfunction}

Wakefield (1992) has argued that it may be helpful to understand mental disorder as 'harmful dysfunction': a combination of a normative illness account and a descriptive account of loss of function, as determined by evolution. Other theorists have argued that the evaluative/normative aspect of
Box 2 Concepts of health disorders

The following are much debated

Illness: subjective experience, includes suffering?

Disease: the pathological processes underlying illness?

Dysfunction: failure of normal action?

Disability: a chronic dysfunctional state?

Disorder: all of the above?

Relevance of statistical deviance from norms?

diagnosis is an essential feature of both physical and mental disorders (e.g. Fulford, 1989; Engelhardt, 1999), and mental disorders therefore need not be seen as something conceptually different. The fact that value judgements may be part of diagnosis does not mean that there cannot be agreement between clinicians, or that the disorder is less 'real' (Fulford, 2000).

\section{Negatively evaluated behaviour}

Few of these theorists have applied their analysis to personality disorder. Formalised diagnostic criteria, such as the DSM or ICD, have tended to equate symptoms with negatively evaluated behaviours, such as deliberate self-harm or violence to others. This causes conceptual problems because usual accounts of illness, and illness behaviour, define 'symptoms' as actions or experiences that are not willed, desired or chosen by the patient. However, negatively evaluated behaviour is so evaluated precisely because it is perceived to be chosen or willed by the patient, and behaviours or experiences that are willed or chosen are not symptoms.

Behaviours and symptoms cannot always be synonymous, especially in the domain of negatively evaluated behaviour. Therefore a theoretical approach that classifies or understands personality disorder in terms of behaviour leads to two problems. Either any negatively evaluated behaviour, such as self-harm or violence to others, is seen as actually willed 'badness' (leaving aside for a moment what that might mean), and people with personality disorders are equated with people who behave badly; or it may be argued that 'bad' behaviour is not a feature of illness, and therefore people with personality disorder are not ill (e.g. Eldergill, 1999).

There are real philosophical objections, and empirical difficulties, with both positions. One principal objection is that 'bad' behaviour can be associated (but is not synonymous) with some types 
of mental illness, as demonstrated by the risk and mental disorder literature. Another objection is the albeit limited evidence that some aspects of 'bad' behaviour have a neurological substrate, and may be influenced by genes for arousal and affect control; whether this would be sufficient to justify the definition of personality disorder as an 'illness' is a moot point in itself.

Focusing on negatively evaluated behaviours as symptoms distracts attention from other ways of conceptualising 'personality disorder'. More recent accounts (including DSM-IV; American Psychiatric Association, 1994) emphasise the significant failure of interpersonal functioning seen in personality disorder, which arises as a result of a variety of psychological deficits (Blackburn, 1998). Some psychiatrists have argued strongly that personality disorder is an illness on the grounds of resulting biological disadvantage to the individual (Gunn, 1992, 1999). Other clinicians have noted the degree of subjective suffering experienced by patients with personality disorder (Norton, 1996), which would normally be understood as a necessary (although not sufficient) feature of an illness. Many studies have noted that patients with personality disorder frequently also suffer from other concurrent mental illnesses, such as anxiety, mood disorders and schizophrenia. Taylor (1999) has argued that one can claim personality to be an illness in so far as it reduces individual variance; people with personality disorder are more like each other than not.

\section{The sickness role}

A possible solution to the problems described above may lie in Talcott Parsons' notion of the 'sickness role'. People who are ill are expected to avoid behaving in ways that exacerbate their condition, accept the idea that they need help, have the desire to get better and seek competent help to do so (Mechanic, 1978). However, many people with personality disorders, although claiming to be ill and in need, do not behave in the ways expected of a sick person. Perhaps we could understand this failure to fulfil sick role expectations as a type of psychological disability - an incapacity to obtain care effectively - which would undoubtedly convey a biological disadvantage in the long term.

\section{Disability}

Fulford (1989) has argued that it might be helpful to understand personality disorders as disabilities, rather than illnesses. Accounts of disability usually emphasise the chronic nature of the patient's problems; they also emphasise the interpersonal
Box 3 Personality disorder and concepts of health

Is personality disorder:

- an illness (suffering; biological disadvantage)?

- a pejorative label, used to describe 'bad' behaviour?

- caused by a disease process (amygdala dysfunction, abnormal arousal patterns)?

- acquired as a result of adverse or traumatic environmental experience?

- another term for 'deviant' or 'criminal', and nothing to do with health?

- a complex manifestation of multiple disabilities?

- all/ none/some of the above?

aspects of function and dysfunction for people with disabilities. Some readers may remember an advertising campaign for people with disabilities that ran the slogan "Our biggest handicap is other people's attitudes". Such an interpersonal view is found in American legal definitions of disability (Silver, 1999) and it may be a useful way to understand the difficulties faced by people with disability in terms of making choices and being agents of their own destiny (Agich, 1993).

\section{Is personality disorder an illness?}

The status of personality disorder as an illness therefore remains contentious, especially while it is defined simply in terms of behaviour. Scadding (1988) has argued that most accounts of mental disorder are at a syndromal, or symptom level, and that illness claims are stronger when there is an aetiological account. Aetiological models have only recently been developed for personality disorder. These models draw on research from longitudinal follow-up studies of child development, and the impact of traumatic events of the personality functioning of adults. Both retrospective and longitudinal studies suggest that early childhood adversity is a potent risk factor for the development of a personality disorder in adulthood (Modestin et al, 1998; Johnson et al, 1999). Studies of the effects of exposure in adulthood to traumatic and frightening events also indicate that such events may cause change and damage to the personality (as found in the diagnosis of 'enduring personality change after trauma', defined in ICD-10; World Health Organization, 1992). 
If external events in both childhood and adulthood can shape adult personality functioning, then it is possible to understand personality disorder as an acquired, rather than an innate, condition. Although this argument will not deal with all the conceptual difficulties surrounding the disease/ illness status of personality disorder, it does at least challenge the view that some people are just 'born' with personality disorder - a sort of psychiatric version of St Augustine's notion of original sin.

\section{Treatment and treatability: general medical considerations}

I want now to think about what it means to be able to treat a disorder, any clinical disorder. Treatments may have different purposes, not all of which aim at cure. Several recent court judgements about treatments for physical diseases have made it clear that 'treatment' includes a broad range of interventions aimed at bringing about a beneficial outcome; and this benefit may be defined as change of symptoms, enhancement of quality of life or prevention of further damage.

\section{Seven-factor model of treatability}

What makes a physical condition treatable? I would like to suggest that treatability is a function of seven factors operating simultaneously (Box 4). No one factor will determine a condition's treatability and, especially, its 'untreatability'.

We can apply this model to any disorder. I will take as an example the treatment of cancer, partly because it is a disorder that sometimes attracts fear and stigma as well as sympathy, and partly because the term 'untreatable' is a term of significance for cancer patients and their families.

The type of cancer is a crucial factor in looking at treatability and prognosis, since it is well established that different types may be more or less treatable. The treatability of the cancer will depend on its anatomical context (site) and nature (e.g. histological grading, differentiation). The spread of the cancer affects its treatability - more extensive spread may make some types of treatment more difficult. Premorbid health is a relevant factor in assessing treatability, in so far as it reveals risk and resilience factors that may affect the course of the disorder.

The timing of any treatment for cancer influences treatability, given that there is evidence supporting
Box 4 The seven-factor model of treatability

1 The nature and severity of pathology: site, histology, grade

2 The involvement of other bodily systems: spread, impact on function

3 The patient's previous health, comorbidity, risk factors

4 The timing of intervention: diagnosis, early/late identification, action

5 The experience and availability of staff

6 Availability of specialist units for special conditions

7 State of knowledge; cultural attitudes

early rather than late intervention. This in turn relates to the process of diagnosis and identification of the problem. In many cases, treatment is delayed, either because symptoms are not understood as being those of cancer, or because symptoms are thought to be caused by another condition. Such uncertainty about identification of symptoms and diagnosis can lead to delay, which in turn affects treatment response.

Once detected, treatability is affected by the availability of specialists familiar with the specific problems posed by different sorts of cancer. There is good evidence, for example, that the treatability (and prognosis) of breast cancer is influenced by the availability of specialist breast cancer surgeons. Such specialists are backed up by specialist teams, with access to specialist facilities and equipment. Such specialist treatment rarely provides a cure for the cancer; nevertheless, therapy is still offered that improves quality of life and offers support to those who care for and support the patient.

Lastly, most cancers are more treatable now than 10 or 15 years ago: better understanding of the different conditions, their course and nature have offered improved ways of offering treatment. Very few cancer treatments, especially for severe conditions, have been exposed to randomised controlled trials to prove their efficacy; yet they are used clinically to good effect. It is also worth considering the strong ethical arguments against carrying out such trials.

\section{Application of the seven-factor model to personality disorder}

I hope it will already be apparent that there are parallels between the treatment of cancer and the treatment of personality disorder. In relation to 
diagnosis, a simple statement of 'personality disorder' is likely to be misleading. Most individuals can be diagnosed as having more than one personality disorder, indicating a range of difficulties. The predominant type is relevant, however, because different interventions may be indicated for different types of personality disorder (Davidson, 2001). The evidence base for treatment of personality disorder generally is still limited, but this concern is more a feature of Factor 7 (i.e. state of scientific knowledge) than a characteristic of the disorder itself. It is also worth remembering that 20 or 30 years ago, 'cancer' was also treated as a somewhat unitary diagnostic identity with a gloomy prognosis.

\section{Factor 1: Nature and severity}

Whatever the limitations of the current typologies, it is clear that not all personality disorders are the same. It is also clear that there are degrees of severity; the term 'severe personality disorder' has been in usage for over 30 years (e.g. Craft et al, 1964; Department of Health/Home Office, 1986; Tyrer \& Johnson, 1996) and is not simply a contemporary political invention. Equally, it is likely that there are both 'mild' and 'moderate' degrees of personality disorder, characterised by significant interpersonal dysfunction, but without the more extreme behavioural manifestations. These conditions may be made worse by the presence of other factors, such as Axis I disorders, or new stressors. Such a dimensional approach provides a better description of the clinical complexities observed in practice. The evidence to date suggests that mild and moderate severe personality disorders are treatable with appropriate therapeutic interventions (Fonagy \& Roth, 1996; Lees et al, 1999).

\section{Factor 2: Degree of spread}

In the case of personality disorder, 'spread' would be represented by the patient's degree of involvement in other psychological, health and social systems, and the impact on functioning in different areas of their life (Remington \& Tyrer, 1979). Different degrees of involvement with different systems could be seen as a measure of severity; that is, an individual who has been involved with health, social and criminal justice systems as a result of a personality disorder is likely to be less treatable than one who has been involved only with health care providers. Severity may also be indicated by the frequency, variety and harmfulness of any risk behaviours. Such an approach is supported by the literature on mental disorder and risk, which indicates that risk factors are additive (Swanson, 1994). The emphasis is on understanding the behaviours as manifestations of interpersonal dysfunction, just as abnormal gait may be a behavioural manifestation of metastatic disease.

\section{Factor 3: Comorbidity}

The treatability of any disorder is likely to be reduced when there is comorbidity with other disorders. This is frequently the case for personality disorder, where comorbidity with mood disorders and substance misuse are especially common. Treatability is also likely to be affected by developmental history, and the presence of risk and resilience factors. For example, most therapists assessing the treatability of personality disorder will look at the history of interpersonal relating from early childhood, arguing that treatment is more likely to be successful if there is any history of a positive attachment to another person.

\section{Factor 4: Identification, diagnosis and timing}

Clearly, personality disorder will be not be 'treatable' if it is not identified as a disorder: hence the relevance of the illness debate discussed above. There are empirical questions to be answered here: if two individuals with similar presentations are assessed, and both are understood as having a personality disorder but only one is treated, what difference does that make to subsequent treatability? Do early interventions prevent later pathology? Ongoing studies of adolescents with personality disorder may provide information about this: what is established is that patients with personality disorder are unpopular and rejected by services (Appleby \& Lewis, 1988). The point here is whether the process of rejection, and failure to identify pathology, itself affects the treatability of the condition, so that each negative encounter makes the condition worse.

\section{Factors 5 and 6: Specialist staff and facilities}

Factors 5 and 6 relate to the provision of specialist staff and facilities. Clinicians who either do not accept personality disorder as a pathological condition, or who have no experience in treating the condition even if they do, may well be justified in saying that personality disorder is untreatable by them or in their units. The issue here is that factors outside the patient's condition may make them untreatable, rather than some innate feature of their condition. Given what we know about the adverse early childhood experience in personality disorder and the difficulties in constructive help-seeking that is often a feature, it is very unlikely that many individuals with personality disorders will be 'treatable' in facilities that require them to be obedient, compliant, passive and grateful. 
A claim that treatability may be a function of service availability is further supported by evidence that where specialist help is provided, both in terms of staff and facilities, therapeutic benefits are possible in some types of personality disorder (Dolan et al, 1996; Bateman \& Fonagy, 1999; Lees et al, 1999; Perry et al 1999). The case is then no different from that of some types of cancer, where effective therapeutic interventions will only be offerable by some specialist units. No one would argue that conditions such as cancer are globally 'untreatable', only that treatment and treatability may be limited by access to and availability of trained staff.

Availability of specialist staff and services raises the question of resource allocation in the treatment of personality disorder. It is not possible to quantify exactly the resources needed, although some estimate might be made based on primary care prevalence figures and usage of services at all levels. Some evidence exists that demonstrates that where specialist therapy is offered and completed, the costs involved are offset by the subsequent reduction of service usage by patients with personality disorder (Dolan et al, 1996). Resource allocation in medicine generally is a complex ethical decision-making process. To date, allocation of resources for the treatment of mental disorders has favoured the needs of those with chronic psychotic disorders, who may be seen as more deserving, more conventionally 'ill' and easier to treat with medication that is cheap. Resources for the treatment of personality disorder tend to become available when required as a means of controlling violence to third parties, which reinforces the conflation of a personality disorder diagnosis with violence. Even in the context of violence, resources are not concentrated on those patients with personality disorder who are violent to partners or children, but rather on the minority who are more generally violent, often in bizarre ways.

Factor 7: Scientific knowledge and cultural attidutes

Factor 7 involves the state of scientific knowledge, and the influence of both that evidence base and cultural attitudes on treatability of personality disorder. There has been a real increase in the scientific study of personality disorder over the past 10 years (Gunn, 1999), but there is still extensive empirical ground to make up. Basic knowledge about the natural history, course and prognosis are still lacking - a review published 10 years ago raises many questions to which there are still no answers (Tyrer et al, 1991). Given such a lack of evidence, it seems illogical (not to say irrational) to state categorically that personality disorder is not an illness because it does not have an established course or prognosis (Ferguson \& Milton, 2000).

An evidenced-based position supports two claims about personality disorder that are important in considering treatability. First, the evidence that personality disorder may in part be an acquired condition justifies clinicians taking time to think in more complex ways about individuals with personality disorders. Second, there is good evidence that some types of personality disorder, probably of mildto-moderate severity, do respond to some types of treatment - usually a combination of psychological and pharmacological interventions delivered by clinical teams with experience and training. There is therefore no justification for global assertions that personality disorder is untreatable - a view that is still taught to trainees, asserted in journals and stated as expert evidence in court.

There is equally no evidence that all personality disorders would be treatable if only the clinician's attitude were right and there were enough facilities. A grandiose attitude to the management of personality disorder may be as damaging as a nihilistic one (Cawthra, 2000). Just as in other medical domains, there are likely to be many cases where the damage is so great, and the interpersonal systems failure so profound, that no treatment is going to bring about improvement for the individual. To date, we have no evidence that therapies are available that can ameliorate severe personality disorder which gives rise to significant harm to self and others.

However, people with severe personality disorders arguably may still require interventions that are therapeutic, or at least not anti-therapeutic. Their needs resemble those cases in palliative care where interventions are still offered, if only in terms of a supportive environment and support for staff who are involved in the daily management of such cases. Alternatively, if one understood these people as cases of severe disability (picking up Fulford's argument), therapeutic interventions could be aimed at damage limitation, quality of life issues and the management of despair and grief at what has been lost and cannot be repaired.

\section{Conclusions}

$$
\begin{aligned}
& \text { "If you can meet with triumph and disaster, } \\
& \text { and treat those two impostors just the same." } \\
& \text { Rudyard Kipling }
\end{aligned}
$$

My argument here is that the assessment of treatability of personality disorder is a complex process, which is multifactorial and operational in nature. The approach outlined above is clearly only 
a preliminary account, which could be further developed. Such an approach might generate ways of rating treatability, which could then be assessed empirically for validity and reliability in different clinical settings.

I have outlined some of the factors I consider to be central to providing a good quality assessment of treatability; no doubt there are others that will be relevant. For example, I have not discussed the question of repeat assessment, which would take account of both temporal change and the interpersonal nature of the dysfunction to be assessed. One-off assessments alone may be highly unreliable (Bass \& Murphy, 1995). Motivation is important, since individuals with personality disorder (like any other patient group) may also be more or less willing to get engaged in treatment, depending on circumstances. Paradoxically, a time of crisis may not be the best time to start some types of treatment; different treatments may be more or less appropriate at different times.

I will close by thinking briefly about the implications of this discussion for services. The key message is that not all patients with personality disorder are the same. Different psychiatric services are likely to meet different types of personality disorder, of different levels of severity, and may therefore need to develop different therapeutic approaches. Clearly, specialist services for personality disorder will be able to offer interventions that cannot be offered in primary care; however, it may be a mistake to generalise from those specialist services to less specialist general ones.

Three different service providers may have specific roles to play. Psychotherapy services will be important providers, not just of highly specialised services such as out-patient and in-patient therapeutic communities, but also as sources of advice, consultation and supervision to adult mental health and primary care (NHS Executive, 1996). Child and adolescent services will be involved with young people whose personality disorder may be more amenable to treatment (which can be empirically studied); they will also see a group of people with personality disorders who are dangerous only to their children. Such individuals arguably also suffer from severe and dangerous personality disorder, but are rarely offered any sort of intervention. Lastly, secure forensic services will probably see people with the most severe and dangerous personality disorders. They will therefore need additional resources in terms of psychological therapists, both medical and non-medical, of all theoretical schools. This is especially necessary in order to develop therapeutic strategies for managing men and women who may have to reside in some sort of secure care for the rest of their lives. As my late and much missed predecessor, Murray Cox, once said: "If no one ever left Broadmoor, you would need more staff not less."

We need to be developing better education and training for junior medical staff and other members of multi-disciplinary teams managing people with personality disorder. Provision of staff education and support, which helps staff to understand the impact of working with patients with personality disorder, makes therapeutic interventions more possible (Norton, 1996) and is valued by staff (Krawitz \& RREAL, 2001). This is not to say that all the problems will vanish, only that they may be more manageable.

Personality disorder still presents considerable conceptual and therapeutic challenges. We still struggle with defining it, diagnosing it and dealing with its more destructive behavioural manifestations. As the behaviours become more dangerous and frightening to others, so we have seen that sections of the public, including government, hope that psychiatry can offer something that will make people not just feel better, but behave better. The clinician/researcher who could do such a thing might get a Nobel Prize (and make a lot of money). The more likely course for psychiatrists is that we will continue to have to manage very difficult people with scarce resources; and somehow avoid falling into either angry despair or mindless optimism. As Kipling suggests, 'triumph' and 'disaster' may both be psychological impostors.

\section{Disclaimer}

Although the facts are clinically accurate, Kieran's case is fictitious and does not represent any real patient, alive or dead. The views expressed here are those of the author alone, and do not represent the views of either Broadmoor Hospital Trust, or Camden \& Islington Community Health Services Trust.

\section{References}

Agich, G. (1993) Autonomy in Long-Term Care. Oxford: Oxford University Press.

American Psychiatric Association (1994) Diagnostic and Statistical Manual of Mental Disorders (4th edn) (DSM-IV). Washington, DC: APA.

Appleby, L. \& Lewis, G. (1988) Personality disorder: the patients psychiatrists dislike. British Journal of Psychiatry, 153, 44-49.

Bass, C. \& Murphy, M. (1995) Somatoform and personality disorders: syndromal comorbidity and overlapping developmental pathways. Journal of Psychosomatic Research, 39, 403-427.

Bateman, A. \& Fonagy, P. (1999) Treatment of borderline personality disorder. American Journal of Psychiatry, 156, 1563-1568.

Blackburn, R. (1998) Psychopathy and the contribution of personality to violence. In Psychopathy: Antisocial, Criminal and Violent Behaviour (eds T. Millon, E. Simonson, M. Birket-Smith, et al), pp. 50-68. London: Guilford Press. 
Boorse, C. (1975) On the distinction between illness and disease. Philosophy and Public Affairs, 5, 49-68. Reprinted in Lindemann Nelson, J. \& Lindemann Nelson, H. (eds) (1999) Meaning and Medicine: A Reader in the Philosophy of Health Care, pp. 16-27. London: Routledge.

Cawthra, R. (2000) Commentary on Recent developments in borderline personality disorder. Advances in Psychiatric Treatment, 6, 217-218.

Craft, M., Stephenson, G. \& Granger, C. (1964) The relationship between severity of personality disorder and certain adverse childhood influences. British Journal of Psychiatry, 110, 392-396.

Davidson, S. (2001) Therapeutic strategies for personality disorder. Advances in Psychiatric Treatment (in press).

Department of Health (2000) Reforming the Mental Health Act: Part II: High Risk Patients. Cm 5016-2. London: Department of Health.

Department of Health/Home Office (1986) Offenders Suffering from Psychopathic Disorder. Joint Consultation Paper: London: HMSO.

Dolan, B. M., Warren, F. M., Menzies, D., et al (1996) Costoffset following specialist treatment of severe personality disorders. Psychiatric Bulletin, 20, 413-417.

Eldergill, A. (1999) Psychopathy, the law and individual rights. Princeton University Law Journal, III, 1-30.

Engelhardt, T. (1999) The disease of masturbation: value and the concept of disease. In Meaning and Medicine: A Reader in the Philosophy of Health Care (eds J. Lindemann Nelson \& H. Lindemann Nelson), pp. 5-15. London: Routledge.

Ferguson, B. \& Milton, J. (2000) Editorial. Irish Journal of Psychological Medicine, 17, 3-4.

Fonagy, P. \& Roth, P. (1996) What Works for Whom? London: Sage.

Fulford, K. W. (1989) Moral Theory and Medical Practice. Cambridge: Cambridge Uinversity Press.

- (2000) Disordered minds, diseased brains and real people. In Philosophy, Psychiatry and Psychopathy. Personal Identity in Mental Disorder (ed. C. Heginbotham), pp. 47-75. Aldershot: Ashgate Publishing.

Grounds, A. (1987) Detention of 'psychopathic disorder' patients in special hospitals. Critical issues. British Journal of Psychiatry, 151, 474-478.

Gunn, J. (1992) Personality disorders and forensic psychiatry. Criminal Behaviour and Mental Health, 2, 202211.

- (1999) Written evidence. In Department of Health Report of the Committee of Enquiry into the Personality Disorder Unit, Ashworth Special Hospital. Vol. II: Expert Evidence on Personality Disorder, p. 207. Cm4195. London: Stationery Office.

Home Office/Department of Health (1999) Managing Dangerous People with Severe Personality Disorder: Proposals for Policy Development. London: Home Office/ Department of Health.

Johnson, J., Cohen, P., Brown, J., et al (1999) Childhood maltreatment increases risk for personality disorders during early adulthood. Archives of General Psychiatry, 56, 600-606

Kendell, R. (1975) The concept of disease and its implications for psychiatry. British Journal of Psychiatry, 127, 305-315.

Krawitz, R. \& RREAL (Resource Team for Borderline Syndrome) (2001) Borderline personality disorder: foundation training for public mental health clinicians. Australasian Psychiatry, 9, 25-28.

Lees, J., Manning, N. \& Rawlings, B. (1999) Therapeutic Community Effectiveness. NHS Centre Reviews and Dissemination, Report 17. York: University of York.

Mawson, D. (1983) 'Psychopaths' in special hospitals. Psychiatric Bulletin, 7, 178-181.

Mechanic, D. (1978) Medical Sociology (2nd edn). New York: Free Press.

Modestin, J., Oberson, B. \& Erni, T. (1998) Possible antecedents of DSM-III-R personality disorders. Acta Psychiatric Scandinavia, 97, 260-266.
NHS Executive (1996) Review of Psychotherapy Services. London: Department of Health.

Norton, K. (1996) Management of difficult personality disorder patients. Advances in Psychiatric Treatment, 2, 202210.

Perry, J. C., Banon, E. \& Ianni, F. (1999) Effectiveness of psychotherapy for personality disorders. American Journal of Psychiatry, 156, 1312-1321.

Remington, M. \& Tyrer, P. (1979) The social functioning schedule - a brief semi-structured interview. Social Psychiatry, 14, 151-157.

Scadding, J. (1988) Health and disease: what can medicine do for philosophy? Journal of Medical Ethics, 14, 118-124.

Silver, A. (1999) (In)Equality, (Ab)Normality and the Americans with Disabilities Act. In Meaning and Medicine: A Reader in the Philosophy of Health Care (eds J. Lindemann Nelson \& H. Lindemann Nelson), pp. 28-37. London: Routledge.

Swanson, J. (1994) Mental disorder, substance abuse, and community violence: an epidemiological approach. In Mental Disorder and Violence (eds J. Monahan \& H. Steadman), pp. 101-136. Chicago: University of Chicago Press.

Taylor, P. J. (1999) Written evidence. In Department of Health Report of the Committee of Enquiry into the Personality Disorder Unit, Ashworth Special Hospital. Vol. II: Expert Evidence on Personality Disorder, p. 489. Cm4195. London: Stationery Office.

Tyrer, P. \& Johnson, T. (1996) Establishing the severity of personality disorder. American Journal of Psychiatry, 153, 593-597.

—, Casey, P. \& Ferguson, B. (1991) Personality disorder in perspective. British Journal of Psychiatry, 159, 463471 .

Wakefield, J. (1992) Disorder as harmful dysfunction: a conceptual critique of DSM-III-R's definition of mental disorder. Psychological Review, 99, 232-247.

World Health Organisation (1992) International Classification of Mental and Behavioural Disorders (ICD-10). Geneva: WHO.

\section{Multiple choice questions}

1. In nosological terms, personality disorder may be understood as:

a behavioural deviance alone

b distinct from other mental illnesses

c a mental disorder

d a mental disability

e all of the above.

2. Relevant aetiological factors in the genesis of personality disorder include:
a genetic factors
b temperament
c exposure to childhood adversity
$\mathrm{d}$ exposure to trauma in adulthood
e all of the above.

3. The following statements are true of personality disorder:

a 'severe' personality disorder is a recent political invention 


\title{
MCQ answers
}

3

a $\mathrm{F}$

b $\mathbf{T}$

c $\mathbf{F}$

d $\mathbf{F}$

e $\mathbf{T}$ b some types of personality disorder respond to treatment based on a therapeutic community model

c there is evidence for the efficacy of treatment of severe personality disorder

$\mathrm{d}$ personality disorder is untreatable

e some cases of personality disorder are difficult to treat.

\section{Commentary}

\author{
Peter Tyrer
}

When I was a medical student, we were in the halcyon days of therapeutics in psychiatry. Each new treatment, whether it was a new antidepressant or antipsychotic drug, or a new psychological approach such as 'implosion' for phobic anxiety, was greeted with enthusiasm and excitement. The snake pits of mental hospitals, where people had been placed because they were incurable, were on the way out, carried away into the distance by this wave of therapeutic optimism, where everything that came into the ambit of psychiatry was potentially treatable. Indeed, such was this optimism that when a wise old bird like Desmond Curran, doyen of psychiatry at St George's Hospital, argued against this in favour of 'Psychiatry Ltd' (1952) he was regarded as in his dotage by the young therapeutic turks and ignored.

My, how times have changed. None of Adshead's (2001, this issue) seven factors of treatability ever entered our heads. The nature and severity of the pathology we were treating was immaterial. William Sargant, who taught generations of medical students that they would be on to a winner if they entered psychiatry, shouted at us that it did not matter if we had only the foggiest idea of the changes in the brain in depression; what did matter was that antidepressants worked, and we should use them in the same way that quinine was used to treat malaria before the protozoan parasite was discovered. The extent of involvement of other bodily systems and coincidental morbidity was also immaterial; this was the age of empiricism, when experiment was everything. As for diagnosis, this was easy. You found out whether your treatment was effective and, if it was, the condition could be labelled accordingly. Thus, when the wide spectrum of efficacy of antidepressants became known, we had masked, atypical, hysteroid and hypochondriacal depression, all of which were trumped by the Italian 'depressione sine depressione', which allowed all conditions to be treated logically with antidepressant drugs. The questions as to whether sufficient staff or facilities were available to treat the disorders concerned and the cultural implications of so doing also fell by the wayside. If there was a treatment that worked, it was up to the frontline staff to provide it; nothing more needed to be said.

Although these views now seem utterly outdated and stereotypical, they have some relevance to Adshead's article. Many of the obstacles to successful treatment outlined so eloquently by her

Peter Tyrer is Professor of Community Psychiatry at Imperial College School of Medicine (St Mary's Hospital, Paterson Centre, 20 South Wharf Road, London W2 1PD) 